\title{
Armed, Prohibited and Violent at Home: Implementation and Enforcement of Restrictions on Gun Possession by Domestic Violence Offenders in Four U.S. Localities
}

\author{
Shannon Frattaroli ${ }^{1}$ (D) April M. Zeoli ${ }^{2} \cdot$ Daniel W. Webster $^{1}$
}

Accepted: 20 December 2020 / Published online: 4 January 2021

(C) The Author(s) 2021

\begin{abstract}
Firearms increase the risk of lethality in violent intimate relationships. Policies that restrict access to firearms by respondents to civil domestic violence protective orders (DVROs) are associated with reductions in intimate partner homicide, yet there is scant literature about how such prohibitions are implemented. We document how four localities are implementing gun possession prohibitions that result from civil and criminal restraining orders and domestic violence misdemeanor convictions; and assess the findings in the context of Kingdon's agenda setting framework. We identified four jurisdictions where gun dispossession of prohibited domestic violence offenders was underway and collected data through in-depth interviews, site visits, and documents. We coded the data, identified explanatory themes, and compared the findings to Kingdon's framework. The four jurisdictions have policies ranging from no state laws restricting domestic violence offenders' access to guns to comprehensive state laws. We describe implementation initiatives to dispossess prohibited people of their guns in the four jurisdictions, two distinct implementation models through which gun dispossession occurs, and an expanded application of Kingdon's model. In each jurisdiction, we identified one or more individuals who championed implementation. Policies that prohibit domestic violence offenders from possessing guns are promising, and possible in diverse settings and jurisdictions. Here we provide insight into implementation efforts in four jurisdictions, emphasize the role of individuals in prioritizing implementation, and highlight the potential to realize these restrictions across states with different laws. Focusing on implementation is a much-needed paradigm shift that complements the traditional focus on passing domestic violence prevention laws.
\end{abstract}

Keywords Firearms $\cdot$ Domestic violence $\cdot$ Implementation $\cdot$ Restraining orders $\cdot$ Policy

\section{Introduction}

Intimate partner violence (IPV) often involves a pattern of behaviors used by one partner to control the other. Abusers'

Shannon Frattaroli

Sfratta1@jhu.edu

April M. Zeoli

Zeoli@msu.edu

Daniel W. Webster

Dwebster@jhu.edu

1 Center for Gun Violence Prevention and Policy, The Johns Hopkins Bloomberg School of Public Health, 624 North Broadway, 5th Floor, MD 21205 Baltimore, USA

2 School of Criminal Justice, Michigan State University, 655 Auditorium Road, East Lansing, MI 48824, USA controlling behaviors sometimes include using firearms to intimidate or threaten (ex)partners, which can escalate to serious injuries and deaths (Lynch and Logan 2015; Sorenson and Schut 2018; Campbell et al. 2003). While state laws vary (Zeoli et al. 2019), under certain legal conditions, such as conviction for a misdemeanor crime of domestic violence or being a respondent to a restraining order, an IPV offender may be prohibited from possessing firearms. One question that many communities are wrestling with is how to enforce this restriction when a newly prohibited person already possesses a firearm. In other words, how will agencies within the justice system identify newly prohibited individuals and assure any firearms in their possession are safely removed? Some jurisdictions have already answered these questions and have policies and protocols in place for offenders to relinquish any firearms they (now illegally) possess. How those policies and protocols were developed and are being implemented is the focus of this research. 


\section{Literature Review}

Data from the National Crime Victimization Survey (2003 to 2012) suggest that firearms are used in $3.4 \%$ of IPV events (Truman and Morgan 2014). This is similar to earlier estimates of $3.5 \%$ of American women who reported being threatened with a firearm and $0.7 \%$ who reported having a firearm used against them by their intimate partners (Tjaden and Thoennes 2000). While firearms are used in a minority of IPV events, Sorenson (2017) used population estimates to determine that these percentages are commensurate with 4.5 million women threatened and 900,000 women who had firearms used against them by their intimate partners in their lifetimes.

Intimate partners are often not the sole focus of their abusers' firearm violence. While research in this area is limited, one study suggests that a small percentage of IPV offenders who use or threaten to use firearms against their intimate partners also use firearms to threaten their children (Sorenson and Wiebe 2004). The literature also includes documentation of IPV offenders who threaten to harm or kill their children, but those studies do not specify whether firearms were part of those threats (Campbell et al. 2003; Moracco et al. 2006). IPV survivors report that the presence or threat of a firearm increases their danger (Folkes et al. 2013; Lynch and Logan 2015; Sorenson 2017; Sorenson and Wiebe 2004). This increased sense of danger and possible threats against their children make firearms effective tools for IPV offenders to use to control their victims, as a victim is more likely to obey an abuser with a firearm (Sorenson and Schut 2018).

When a firearm is used during a physically abusive IPV event, the attack is more likely to be deadly than if the abuser used a knife, other weapon, or bodily force (Saltzman et al. 1992). In fact, research suggests that when a male IPV offender has access to a firearm, it increases the risk of femicide ${ }^{1}$ by 400\% (Campbell et al. 2003). Indeed, most intimate partner homicides are committed with firearms (Fox and Fridel 2017), and just under three-quarters of multiple victim intimate partner homicides in some states are firearm homicides (Smith et al. 2014; Smucker et al. 2018). More recently, the threat of firearm violence has also been associated with posttraumatic stress disorder among IPV victims as well (Sullivan and Weiss 2017).

For some IPV offenders, their violence and victims extend outside of the home and family relationships. Indeed, specialization in only domestic violence is rare, with most domestic violence offenders having criminal records for other, including violent, crimes (Keilitz et al. 1997; Richards et al. 2013). A review of 89 known shooters implicated in 73 mass shootings between 2017 and 2019 revealed that 17 (19\%) had

\footnotetext{
${ }^{1}$ Femicide is the intentional killing of a woman, by a man, because of her gender.
}

documented justice system involvement for IPV. While none of these 17 had a current domestic violence restraining order (DVRO), 4 had been a respondent in the past and 6 had been convicted of a domestic violence crime (Zeoli and Paruk 2019).

Given the seriousness of firearm use in IPV, the federal government and many states restrict certain groups of IPV offenders from purchasing and possessing firearms: those currently under certain DVROs and those convicted of misdemeanor crimes of domestic violence. ${ }^{2}$ Only one study has examined whether laws requiring relinquishment of firearms from those convicted of domestic violence misdemeanors is associated with intimate partner homicide (Diez et al. 2017), and this study found no association.

There is a more extensive and robust literature related to civil restraining order laws. IPV victims in all 50 states can petition the court for a civil DVRO with the goal of preventing future violence. Judges evaluate those petitions and decide whether to grant the orders and which remedies (e.g., prohibited behaviors, prohibited contact) to include. Based on state and federal law, some DVROs prohibit respondents from purchasing and possessing firearms. Laws prohibiting firearm purchase and possession for respondents to DVROs are associated with reductions in intimate partner homicide rates (Vigdor and Mercy 2006; Zeoli and Webster 2010; Zeoli et al. 2018). Some state laws authorize judges to require respondents to DVROs relinquish their firearms (Zeoli et al. 2019). Two studies of these laws found that the protective impacts of DVRO firearm restrictions on intimate partner homicide rates are contingent upon the legal authority to require firearm dispossession (Diez et al. 2017; Zeoli et al. 2018).

New firearm purchases may be prohibited through background check systems that include disqualifying DVROs and misdemeanor convictions. In practice prohibited individuals may continue to possess firearms they owned prior to their disqualifying records if the justice system does not take steps to ensure that those newly prohibited relinquish their guns (Webster et al. 2010). This may be due to the lack of protocols and systems for recovering firearms from prohibited persons and is a missed implementation opportunity to improve victim safety (Frattaroli and Teret 2006).

When an individual is charged with a domestic violence crime, there is an additional opportunity to prohibit them from purchasing and possessing firearms through criminal restraining orders. Criminal restraining order laws differ among the states where they exist, but in general they are conceptually similar to civil restraining orders (Sullivan et al. 2017). One critical procedural difference is that prosecutors, not IPV victims, request the

\footnotetext{
${ }^{2}$ While we use the term "intimate partner violence" to refer to violence directed toward one's current or former spouse, dating partner, or co-parent, the term used in federal and state laws to describe this phenomenon is "domestic violence." Because the term "domestic violence" may also describe violence toward other family members, we use "intimate partner violence" for greater precision except when discussing the laws.
} 
court issue a criminal restraining order. Depending on state law, this could happen at different points during the criminal process, from a bail hearing through to sentencing after conviction. Firearm prohibitions may be included in these criminal restraining orders, which may specify dispossession requirements. Much of the focus in the literature on firearm dispossession involves civil DVROs, but attention to firearm relinquishment by those facing or convicted of criminal charges or who are subject to criminal restraining orders is also warranted (Sullivan et al. 2017).

While many states have firearm relinquishment laws, there is little practice guidance or scholarship about how to implement these laws or how implementation occurs (Frattaroli and Teret 2006; Wintemute et al. 2014; Prosecutors Against Gun Violence and The Consortium for Risk-Based Firearm Policy 2016). Despite the wide-ranging impacts of armed batterers for families and communities, many jurisdictions do not have protocols in place for implementation of firearm relinquishment policies, struggle with this process, and/or do not prioritize assuring these laws are implemented. Attention to implementation of DVRO and criminal restraining order firearm possession prohibitions is important because relying on newly prohibited individuals to relinquish firearms without any additional law enforcement action is unlikely to result in gun dispossession. Protocols are needed to provide guidance about how to access resources to identify whether and how many guns a newly prohibited person may possess; serve orders and explain dispossession safely; determine where and how relinquished firearms will be stored; and determine processes for returning guns when the prohibition ends and whether the person is legally eligible to possess firearms.

Two aspects of the policy literature guided our approach to considering how implementation of firearm relinquishment for those newly prohibited from possession under DVROs and criminal restraining orders occurs. First, we relied on an early case study of the firearm prohibition of Maryland's civil DVRO law that was informed by the policy implementation literature (Frattaroli and Teret 2006) and a later examination of a similar California law (Wintemute et al. 2014). These contributions provide insight into how firearm relinquishment implementation processes are working in select jurisdictions in Maryland and California and apply concepts from the implementation literature (e.g., the importance of people and policy details) to explain the processes described. As such, we used these studies as a general organizing framework for how to structure our interview guides and approach data collection and analysis.

Second, Kingdon's theory of agenda setting was also instructive and provided a mechanism to further the analyses of the previous studies (Kingdon 2011). While Kingdon's work has long provided a framework for understanding why some policy proposals succeed and others fail, here we assess the relevance of this theory to the implementation phase of the policy process. Kingdon's theory focuses on three streams, or constructs, that emphasize the problem, policy, and politics in creating circumstances under which policy action will occur (Kingdon 2011). In this model, policy entrepreneurs serve as champions for a policy idea by helping to manage the three streams with the goal of elevating their proposal on policymakers' agendas. Given that implementation of firearm dispossession from DVRO respondents is relatively rare among jurisdictions within states where the policy is constant and the context is similar (Diviney, Parekh, Olson, 2009; Frattaroli and Teret 2006; Webster et al. 2010), we viewed the initiation and sustainment of policy implementation within Kingdon's theory as a policy proposal. The role of implementers (judges, prosecutors, law enforcement officers) are important to understanding implementation activities (such as organizing stakeholders to work on the problem, developing protocols, and ensuring those protocols are carried out) and considered their roles in the context of Kingdon's policy entrepreneur. We are unaware of any adaptation of Kingdon's theory to implementation processes.

We designed a qualitative multiple case study to understand how selected jurisdictions implemented and enforced firearm possession prohibitions for civil DVROs, domestic violence criminal convictions, or criminal restraining orders and the factors that influenced implementation and enforcement. We then assessed the case findings within Kingdon's agenda setting framework. Our initial research question focused on relinquishment through civil restraining orders however, throughout the course of our interviews, interviewees routinely discussed enforcement of restrictions on criminal restraining orders and, to a lesser extent, convictions. This perspective on relinquishment following service of criminal restraining orders is therefore the focus of this paper, and addresses a critical gap in the literature, as previously noted. That said, we also discuss civil DVROs and criminal convictions when interviewees highlighted their firearm dispossession efforts related to those laws.

\section{Method}

We chose our study sites through a multi-stage process. First, we reached out to our contacts in the field and used media, meeting presentations, and publications from agencies and organizations on firearm relinquishment practices to identify jurisdictions where law enforcement was implementing and enforcing the firearm possession prohibition for DVROs. Due to our ongoing work, we had a sense of which jurisdictions were engaging in dispossession. We selected jurisdictions within states that reflected a range of domestic violencerelated firearm restriction laws, from states with comprehensive laws to states with no state-level domestic violence firearm restriction laws. We narrowed our list to jurisdictions in 
states that would provide regional and policy diversity. We then reached out to potential contacts in these jurisdictions to assess access, and finalized our four sites based on this information.

We analyzed the resulting data using a cross-case comparative approach. Our data included interviews with key informants who were part of the creation of and/or charged with implementing and enforcing domestic violence firearm restrictions. ${ }^{3}$ This purposive sampling of key informants who created and/or were charged with implementing and enforcing these policies resulted in a sample comprised of individuals who were well-informed and experienced with the firearm dispossession policies and protocols and therefore wellpositioned to identify facilitators and barriers to implementation. Key informant interviewing is a method designed to recognize and value the expertise of those with knowledge about and experience with complex topics, such as the implementation processes that are the focus of the present study (Marshall 1996). This sampling approach that targets experts is aligned with the method. We designed the case studies to create depth of understanding in selected sites for the purpose of informing theory, as opposed to generalizing to other places and actors. However, lessons learned from these sites may be useful to law enforcement, policymakers, and domestic violence service providers in other jurisdictions seeking to improve implementation and enforcement of firearm possession restrictions.

The Michigan State University Institutional Review Board reviewed and approved this study. Prior to the start of each interview, we reviewed a disclosure statement that explained to interviewees that their identities would remain confidential, but that it was possible that some may be able to guess that they had participated based on their roles within their respective organizations.

\section{Key Informant Selection}

We initially used purposive sampling (Miles and Hubermna 1994) to recruit participants who had some responsibility for prohibiting individuals from possessing firearms (e.g., judges and prosecutors), enforcing those prohibitions (e.g., law enforcement officers), or influencing the process (e.g., defense attorneys and victims' advocates). We also spoke with those who were part of the development of firearm dispossession protocols and processes, who we identified based on their positions within the justice system (e.g., a judge, prosecutor, sheriff). We then used a snowball sampling technique to allow our key informants to recommend others with experience or knowledge of enforcing firearm prohibitions and who would

\footnotetext{
${ }^{3}$ While we focus here on restraining order firearm relinquishment, it must be noted that domestic abusers often have additional involvement in the criminal justice system as a result of their violence, and some efforts may overlap.
}

further inform our research questions. Snowball sampling is a recognized technique within the qualitative methods literature for identifying individuals who are critical to an organization but may not be identifiable to those outside the organization (Miles and Hubermna 1994). We interviewed key informants until we reached data saturation, when no new insights into the implementation processes would likely be gained by additional interviews (Creswell, 2007). We assessed saturation at each site.

The interview protocols for each type of key informant (e.g., judge or law enforcement) differed slightly to reflect each informant's role and responsibilities in the process. We (SF and AZ) conducted the interviews. Depending on the location of the case study sites and availability, we conducted the interviews either in-person or remotely via telephone with either one or both of us participating. Interviews took up to one hour and were audio-recorded and transcribed by a professional transcription service, with interviewees' permission.

\section{Interview Protocol}

We developed a semi-structured interview protocol to explore the domains we identified as central to understanding implementation and enforcement of policies that prohibit domestic violence offenders from purchasing and possessing firearms. Table 1 includes those domains and corresponding sample questions. Consistent with semi-structured interviewing techniques (Creswell, 2007; Patton, 2002), we first asked participants to broadly describe their work to implement and enforce the firearm prohibition and the factors that affect their efforts. We then asked detailed questions about the processes described and the factors that influence their work in this area. When those processes or the factors described did not include explanations reported in the literature (Frattaroli and Teret 2006), we asked specifically about those factors. The protocol and our approach to the interviews were flexible to allow conversations about the domains to develop naturally from the initial questions. Through this approach, we adapted our follow-up questions based on the information revealed through informants' responses. This iterative approach informed the questions we asked within and across cases.

\section{Qualitative Analysis}

We uploaded the transcribed interviews into Atlas Ti and followed Corbin and Strauss's (2008) concept of open coding and Yin's (2014) explanation building approach to guide our coding process. We (SF and AZ) reviewed the interview transcripts and developed an initial set of codes based on concepts repeated in the data and those we deemed important to informing the study aims. Discussions between the two reviewers based on these qualities yielded an initial set of codes. We then complemented that first set of codes with a second set 
Table 1 Domains and Corresponding Sample Questions from the InDepth Interview Guide

\begin{tabular}{|c|c|}
\hline Domain 1 & Background \\
\hline Sample Question & $\begin{array}{l}\text { How does the state law that prohibits respondents to } \\
\text { a DVRO affect your organization? }\end{array}$ \\
\hline Domain 2 & Policy Development and Content of the Law \\
\hline Sample Question & $\begin{array}{l}\text { How does the prohibition on DVRO respondents' } \\
\text { firearm possession address or fail to address } \\
\text { intimate partner violence in the state? }\end{array}$ \\
\hline Domain 3 & Implementing the Firearm Prohibition: Awareness \\
\hline Sample Question & $\begin{array}{l}\text { How do people in your organization learn about the } \\
\text { firearm prohibition law? }\end{array}$ \\
\hline Domain 4 & $\begin{array}{l}\text { Implementing the Firearm Prohibition: Possession } \\
\text { Prohibition }\end{array}$ \\
\hline Sample Question & $\begin{array}{l}\text { Please walk me through the process that begins when } \\
\text { someone becomes newly prohibited because they } \\
\text { are a DVRO respondent, and tell me how your } \\
\text { organization is involved in each of these steps. }\end{array}$ \\
\hline Domain 5 & Role of Petitioners \\
\hline Sample Question & $\begin{array}{l}\text { What is the role of victim support services in this } \\
\text { process? }\end{array}$ \\
\hline Domain 6 & Overall Experience \\
\hline $\begin{array}{l}\text { Sample } \\
\text { Questions }\end{array}$ & $\begin{array}{l}\text { Are there cases for which you did not recover guns } \\
\text { when you thought you should? } \\
\text { How do you verify that the prohibited person does } \\
\text { not have guns? }\end{array}$ \\
\hline Domain 7 & Resources \\
\hline $\begin{array}{l}\text { Sample } \\
\text { Questions }\end{array}$ & $\begin{array}{l}\text { Who are the other people/agencies relevant to } \\
\text { enforcing this law? } \\
\text { Why are they important? } \\
\text { How do you work with those } \\
\text { individuals/organizations? }\end{array}$ \\
\hline Domain 8 & Implementation Impact \\
\hline Sample Question & How will gun removal affect petitioner safety? \\
\hline Domain 9 & Other State Laws \\
\hline Sample Question & $\begin{array}{l}\text { Does law enforcement have a system in place to } \\
\text { facilitate gun dispossession of people newly } \\
\text { prohibited because of misdemeanor crimes of } \\
\text { domestic violence? } \\
\text { If yes, can you tell me about that process? }\end{array}$ \\
\hline
\end{tabular}

we developed a priori based on the literature, theory, and our study aim. These two sets of codes formed our codebook. The two coders used the codebook to double-coded a sample of transcripts and reviewed those coded text until we reached agreement about the definition of and how to apply each code. We made minor modifications to the resulting codebook throughout the coding process after discussion and agreement.

After completing this initial coding process, we engaged in the process of data display (Miles and Hubermna 1994), designed to reveal systematic patterns in the data and uncover additional themes not detected during coding. Through this process, we developed a comprehensive understanding of barriers and facilitators to implementing the domestic violence firearm restrictions in each site, and explanations of the four jurisdictions' implementation processes. With each case study site's qualitative analysis complete, we engaged in cross-case analysis. This enabled us to compare findings from each site and determine overlap and across-site variation. The crosscase analysis revealed common themes and provided practical lessons for the successful removal of firearms from newly prohibited individuals. We do not identify the states, jurisdictions, or interviewees in order to provide interviewees with some anonymity in the information they shared.

\section{Case Study Findings}

Based on our review of available documents, contacts with experts in the field, and our own work, we identified 10 jurisdictions in 7 states where law enforcement was actively engaging in firearm dispossession of newly prohibited domestic violence offenders. Conversations with implementers reduced this number to 6 jurisdictions in 5 states, reflecting efforts that were robust enough to warrant an in-depth study of their efforts. Of those remaining sites, we selected the final four jurisdictions from 4 states to maximize the number of states and regions included, the diversity of firearm laws related to domestic violence, and to vary the political parties in power. All jurisdictions were cities with populations ranging from 200,000 to more than 1 million located in states in the West, Midwest, and South. Political leadership in these states was evenly divided between Democrats and Republicans with each party holding the governor's seat and a majority in the legislatures in two states at the time of data collection.

Our interview sample yielded 27 informants whom we contacted for an interview; 16 agreed to participate and we completed those interviews. Two interviewees each for the jurisdictions from States 1 and 2 participated, as well as 6 from the State 3 jurisdiction and 6 from State 4 . We were unable to secure interviews with the remaining 11 people due to nonresponse ( $n=8$, including 1 from State 1 and 7 from State 4), decline to participate ( $n=1$ from State 4$)$, and a change in position ( $\mathrm{n}=1$ from State 4$)$. One additional potential informant from State 4 participated in a meeting we observed, and we agreed that a separate interview was not needed. This monthly meeting of a multi-disciplinary team of IPV professionals who review active IPV cases and coordinate law enforcement and service supports also informed this case study, as did visits to service sites in the two jurisdictions in States 3 and 4. Our local contacts in all four sites also provided information about IPV service providers and the law enforcement IPV initiatives underway, which provided supplementary information that informed our understanding of the implementation and enforcement processes that are the focus of this research. The findings reflect consensus in these processes among interviewees. 


\section{State Laws Prohibiting Firearm Possession for Domestic Violence Offenses}

For each state, we reviewed three types of state laws: 1) those that prohibit people convicted of domestic violence misdemeanors from purchasing and possessing guns, 2) laws that prohibit people restrained under criminal orders from purchasing and possessing guns for the duration of the order, and 3) civil DVROs that prohibit gun purchase and possession for the duration of the order. Table 2 indicates whether each state has any one of the three types of laws that include a firearm restriction: Civil DVRO law, criminal restraining order law, and misdemeanor crime of domestic violence law. Additionally, for those states with a firearm restriction on any of those laws, the table indicates whether the law includes a provision specifying that relinquishment of any guns already possessed can or must be ordered by the court. All states are subject to federal law that prohibits firearm purchase and possession by anyone subject to a DVRO issued after a hearing where the respondent was notified or who has been convicted of a misdemeanor domestic violence crime (Gun Control Act, Title 18 United States Code $\$ 922(\mathrm{~g})$ 1994, 1996). State laws that duplicate or expand federal law are of interest here because they open the door to state and local enforcement of firearm dispossession interventions.

The law in State 1 prohibits respondents to civil DVROs from possessing firearms and further specifies a firearm dispossession provision for respondents to those orders. State 1 also has a domestic violence criminal restraining order that includes firearm restrictions and a dispossession order, prohibits those convicted of misdemeanor domestic violence crimes from possessing firearms and specifies dispossession provisions. In contrast, State 2 has no domestic violencespecific firearm restriction laws. State 3 prohibits respondents to civil DVROs from possessing firearms and includes dispossession language. A type of criminal restraining order issued at the time of arraignment is available under the law in State 3. This order may include firearm restrictions and dispossession orders. State 4 has a civil DVRO firearm prohibition and a corresponding dispossession provision.

\section{Two Models of Implementation}

The cross-case analysis of the four jurisdictions revealed two models for implementing and enforcing firearm dispossession following disqualifying domestic violence civil and criminal court interventions, what we term the "independent" and "coalition" models. We describe both models here, and follow each with summaries of the two corresponding jurisdictions to provide details and context from the cases that informed our characterization of these models.

Independent Model of Implementation The independent model reflects the processes we observed in the State 1 and State 2 jurisdictions where implementation and enforcement of the criminal restraining order firearm prohibition began with motivated individuals in agencies where leadership supported these efforts. These individuals developed systems within their agencies' infrastructures to prioritize firearm dispossession in accordance with their legal authority that drew on the implementing agencies' strengths.

\section{State 1 (Comprehensive state domestic violence and gun laws)}

The local prosecutor's office in the State 1 jurisdiction prioritizes gun dispossession for those prohibited under the State's criminal restraining order law. For domestic violence criminal cases pursued by the office, a check of the State's firearm sales database to determine firearm ownership is a routine part of the process. The office notes in defendants' electronic case files when the firearm sales database reveals a firearm, resulting in a flag in the file that must be resolved to close the case. The office will remove a flag upon receiving confirmation that the defendant does not have access to the firearms identified in the firearm sales database, either because law enforcement facilitated dispossession of those firearms or because they determined that the defendant was no longer in possession of the identified firearms. Supervising personnel

Table 2 State firearm dispossession laws for domestic violence offenders

\begin{tabular}{lllllll}
\hline State & $\begin{array}{l}\text { Civil DVRO }^{1} \\
\text { firearm restriction }\end{array}$ & $\begin{array}{l}\text { Civil DVRO } \\
\text { relinquish- } \\
\text { ment } \\
\text { specified }\end{array}$ & $\begin{array}{l}\text { Criminal restraining } \\
\text { order may include } \\
\text { firearm restriction }\end{array}$ & $\begin{array}{l}\text { Criminal restraining } \\
\text { order relinquish-ment } \\
\text { specified }\end{array}$ & $\begin{array}{l}\mathrm{MCDV}^{2} \text { firearm } \\
\text { restriction }\end{array}$ & $\begin{array}{l}\mathrm{MCDV}^{2} \text { relinquish-ment } \\
\text { specified }\end{array}$ \\
\hline 1 & $\mathrm{X}$ & $\mathrm{X}$ & $\mathrm{X}$ & $\mathrm{X}$ & $\mathrm{X}$ & $\mathrm{X}$ \\
2 & $\mathrm{X}$ & $\mathrm{X}$ & $\mathrm{X}$ & $\mathrm{X}$ & \\
3 & $\mathrm{X}$ & $\mathrm{X}$ & $\mathrm{X}$ & & & \\
4 & $\mathrm{X}$ & & & & & \\
\hline
\end{tabular}

\footnotetext{
${ }^{1}$ Domestic Violence Restraining Order

${ }^{2}$ Misdemeanor Crime of Domestic Violence
} 
receive regular reports detailing the number of cases with unresolved firearm flags among the cases they oversee. According to interviewees, there is an expectation in this office that when a defendant is identified as illegally possessing firearms, prosecuting attorneys will prioritize dispossession. Similarly, office culture discourages case files that remain open because of unresolved firearm dispossession.

The representatives from the prosecutor's office we interviewed attributed the strength of their implementation approach to two factors. The first is their case management process. From the perspective of interviewees, by automating tracking and oversight of firearm dispossession among newly prohibited defendants, the practice has become a standard part of the workload and work process. Firearm possession data is integrated into the case file and automated e-mail alerts to prosecuting attorneys and their supervisors about defendants with firearms serve to keep the issue front and center. Second, interviewees emphasized that gun violence prevention is a priority for the prosecutor. Staff in the office know that upholding firearm possession prohibitions is valued, and that dispossessing respondents to criminal restraining orders - in particular - has leadership support.

They also explained the success of firearm dispossession by contrasting criminal restraining orders to civil restraining orders, emphasizing the more serious nature of criminal cases. Criminal court involves crimes, punishments, and consequences for non-compliance. In contrast, civil restraining order proceedings have lower evidentiary thresholds, typically do not involve a defense lawyer or a prosecutor, and are not designed to determine guilt or innocence but do have the potential to "promote survivor autonomy, safety, decision-making, empowerment" (Hahn 2018). As one interviewee explained,

The reason why I think we get compliance in our cases is because the defendant is sitting in a criminal court with a judge telling him to turn it [the gun] in and being ordered to come back, with a prosecutor on the other side of the table saying, "We're going to put him in jail if he doesn't comply." I think that's where the power is, I think that's where it's lacking in the civil context where the respondent's in there all by himself and it's just the petitioner, the abused victim on the other side, and a judge making some empty order.

Attempts by this prosecutor's office to expand the case tracking system to include civil orders were unsuccessful, in part, according to one informant, because prosecutors do not have a role in the civil process.

Interviewees from the State 1 jurisdiction cited the State's firearm sale database as the main limitation to their implementation efforts. The office queries the State's firearm sale database for information about defendants' firearm possession. That database includes firearm sales recorded through a licensed firearm dealer, and some private transfers. While the state has a background check requirement for private firearm sales, a growing literature describes low compliance among states with these laws (Miller et al. 2017; CastilloCarniglia et al. 2018; Castillo-Carniglia et al. 2019). With only a partial accounting of firearm transfers, the interviewees know their ability to access information about defendants' firearm possession is limited, with some exceptions, to sales through licensed firearm dealers.

\section{State 2 (No state domestic violence and gun laws)}

Implementation within the State 2 jurisdiction is a joint initiative between the prosecutor's and parole and probation offices that developed in response to a recognized need by probation and parole to keep their clients from committing future violence, frustration with repeat gun violations, and a bench that was unwilling to consistently respond to those violations. As one interviewee described,

... it drove me up the wall that I would have an offender that would get caught after they're legally not allowed to have a gun either committing a new armed robbery or showing up at a victim's house and pointing a pistol at her, or showing up to a victim's house and firing a couple rounds in the ground because they're drunk and angry and they want to talk to her, or any other sort of offense you could think of that they get caught with a weapon later, and there was nothing I could do to hold them accountable for that. Law enforcement didn't take the weapons because they didn't feel they had the authority to do that. ... and usually the judge would not revoke based on them being in possession of a firearm or ammunition when they're not supposed to ...

Therefore, knowledge of illegal firearm possession needed to be met with dispossession action to protect the public's safety. In the absence of a state law prohibiting gun purchase and possession by respondents to civil DVROs and no criminal restraining orders or prohibition on those convicted of domestic violence misdemeanors, this jurisdiction relies on a state parole and probation requirement for participants to comply with federal laws to prohibit gun possession among domestic violence offenders. Interviewees described how those on parole or probation for a domestic violence conviction are subject to federal prohibitions on gun purchase and possession, and violating that federal prohibition constitutes a violation of the terms of their parole or probation under state law. Assuring the federal prohibition on gun possession is upheld and locating this focus on gun restrictions in parole and probation is part of the reason the program has been sustained. As 
interviewees explained, "there's a lot of power and oversight" in the parole and probation authority that holds people accountable to the laws of local, state and federal governments. Add that power to the fact that parolees and probationers are people whom the justice system has concluded are violent, and these firearm dispossession efforts have become accepted practice with leadership support.

This application of parole and probation authority allows local officials in State 2 to enforce the federal prohibition on firearm purchase and possession by people convicted of domestic violence crimes in the absence of a parallel state statute. State 2 also lacks a firearm sales database. Therefore, interviewees rely on court records about defendants' most recent criminal convictions, any additional criminal history, information from victims, and social media for evidence about firearm possession by those in their caseload. Interviewees shared that by searching defendants' public social media accounts, they have been able to obtain photographic evidence of defendants with firearms that they then use to take enforcement action.

Interviewees demonstrated deep knowledge and experience in addressing IPV in their community and described an equally deep network of IPV victim service providers who are committed to reducing IPV and supporting people to address the violence in their lives. Even in the absence of a state law that would allow for firearm dispossession under a restraining order, law enforcement in this jurisdiction developed a strategy consistent with their State's laws to dispossess individuals prohibited under federal law of their firearms in a manner that was in line with their jurisdiction's broader culture of supporting victims.

This independent model resulted in processes that were responsive to newly prohibited individuals by using available firearm sales data to identify guns possessed by those with criminal domestic violence protection orders and engaging prosecutors and police in facilitating dispossession of those guns (State 1). Without a firearm sales database, State 2 implementers relied on information provided by the victim, social media posts, and criminal justice records to identify defendants who may possess guns illegally. This independent model focuses on firearm dispossession and uses available firearm data to prioritize cases and facilitate compliance with criminal restraining order firearm possession prohibitions.

These independent agencies operated with minimal or no collaboration from other agencies. For State 1, the prosecutor's office worked with police when defendants failed to comply with the firearm prohibition, but the police were not described as involved with the planning or oversight of this effort. Because State 2's efforts were focused on probation and parole clients, the partnership between the prosecutor's office and parole and probation did not rely on the services of additional agencies. Despite their independence, interviewees in both states described being available to collaborate with and support partners with an interest in prioritizing firearm dispossession. And in both states, interviewees had reached out to partners engaged with the civil DVRO processes in their jurisdictions and offered to help more fully realize the civil firearm possession prohibitions. However, both offers were declined. This lack of interest in expanding the model beyond those charged with domestic violence crimes was explained in one jurisdiction as reflecting the division between criminal and civil processes and the absence of a clear role for the prosecutor's office in civil processes. Interviewees from the State 2 jurisdiction explained the response as reflective of the well-established processes in place for civil DVROs, and a reluctance to jeopardize the hard-won gains in elevating domestic violence as a serious matter in the civil courts by focusing on firearm dispossession. As detailed in Table 2, State 2 is the least restrictive among the four sets of state domestic violence and firearm laws examined here.

Coalition Model of Implementation Firearm dispossession associated with DVROs and criminal restraining orders occurs under what we define here as a coalition model in the State 3 and State 4 jurisdictions where agencies and non-government service providers work in partnership to provide comprehensive services to IPV victims. Assuring that restraining order respondents comply with the firearms prohibition is one tool among many that implementers in these jurisdictions have to offer the victims they serve. Under this coalition model, the IPV infrastructures in both locales integrate firearm dispossession into victim safety and response.

\section{State 3 (Civil, criminal, and misdemeanor state do- mestic violence and gun laws, no relinquishment specified)}

The State 3 jurisdiction enforces the firearm purchase and possession prohibition of the state domestic violence criminal restraining order and no contact order at arraignment as part of a comprehensive approach to improving victim support. In this jurisdiction, domestic violence stakeholders, including law enforcement (courts, prosecutors, police and sheriffs) and service providers defined firearm dispossession implementation processes after the legislature passed a bill specifying firearm dispossession processes for DVROs. While these groups had a history of working together well, attention to firearms dispossession revealed contrasting opinions about the reach and relevancy of the new law in a locality with high rates of gun ownership and conservative leaning politics. As explained by interviewees, by defining roles and emphasizing dispossession in court when the order is issued, this jurisdiction has established a clear, transparent process that stakeholders support. This implementation process relies on defendants to comply, but also includes a check on compliance. By statute, defendants with firearms must submit proof of relinquishment to the court, and if that does not occur within the 
time period specified by law, then law enforcement will facilitate dispossession. Interviewees reported that the firearm prohibition occurs largely through defendants' compliance.

While the implementation process for assuring firearm prohibition begins at the courthouse, the nature of the relationship among domestic violence stakeholders involves working together to monitor and support victims. As described by interviewees, this coordinated effort provides opportunities to learn from victims about compliance with the firearms prohibition. For example, when law enforcement or advocates hear from a victim that their abuser has firearms and is subject to a restraining order, those involved with the case work with law enforcement to assure dispossession happens. Implementation in this jurisdiction relies on a partnership between law enforcement and victim services providers. These partners share office space and regularly dialogue about how to improve the safety of the victims they monitor with available services and support. Firearm dispossession for those prohibited is one strategy for increasing safety.

Interviewees from the State 3 jurisdiction explained their focus on implementing and enforcing domestic violence firearm prohibitions as important for reducing lethality risk and a cornerstone of their efforts to improve victim safety. This view was often shared in the context of broader references to the State's evolving attention to IPV and the process of refining state laws for firearm violence prevention, in particular, to maximize their impact.

Several interviewees also spoke about the importance of understanding the complexity of domestic violence and how abuse affects victims more broadly. The infrastructures for domestic violence response and services are integrated across the law enforcement agencies and social service organizations we learned about from interviewees and observed during our site visit. One result is an environment in which firearm dispossession is part of the standard procedures and protocols underlying this law that reflects the culture and function of domestic violence response and support within this jurisdiction. The physical space in which program implementers work is also consistent with this context. Law enforcement and service providers share office space that is co-located within a direct service facility where people (almost all women) come for legal assistance, employment support, and counseling. It is a place where children are welcome and on-site social activities provide an opportunity for law enforcement, service providers, and the people they serve to spend time in an informal setting.

\section{State 4 (Civil DVRO state law only)}

The jurisdiction we examined in State 4 also involves a multi-agency response with participants from public agencies (police, sheriffs, courts, parole and probation, judges) and non-profit IPV victim service providers and advocates. This infrastructure is the result of an effort to address IPV that began, by one interviewee's account, in 2009 with the development of a statewide plan that prompted a closer look at how their systems were working. As part of that process, participants raised questions about whether and how firearm dispossession was occurring in cases where the court ordered them removed. As one interviewee explained,

So I can't tell you where or what caused the realization or the question of "We're ordering all these guns to be surrendered, but what's happening?" ... and so we started looking into it and said, "We need to do something here to make sure these are being enforced so that we're at least doing the best we can to get guns out of the hands of people who aren't supposed to have guns." So that was the genesis for it.

The result was a protocol for following up with those newly prohibited from purchasing and possessing firearms - respondents to civil restraining orders and those convicted of domestic violence crimes - and a process for assuring dispossession. By interviewees' admission, the protocol and resulting process are not perfect, and unlikely to result in every ineligible person no longer possessing guns. Nevertheless, some firearms are removed, which is an improvement relative to when no process was in place.

Through our interviews we learned that this infrastructure to support firearm dispossession includes domestic violence specialists with deep knowledge about and commitment to domestic violence prevention in parole and probation, police departments, and the sheriff's office. Dedicated domestic violence positions allow law enforcement practitioners to develop a nuanced understanding of the role of firearms in IPV and the laws available to remove firearms from batterers. They apply that knowledge to their work with individuals who are interacting with the justice system. One result is that law enforcement officials know about the civil restraining order prohibition on firearm possession and take measures to assure that those prohibited are not armed. This commitment to enforce the law extended to those arrested and awaiting trial for domestic violence crimes. Interviewees described reviewing recorded telephone conversations from detention facilities, and following up on reports from victims about batterers possessing firearms as strategies they employ to identify when a defendant possesses firearms.

The efforts within individual agencies are coordinated across stakeholders through monthly meetings that bring together the implementing agencies and victim service providers to review high-risk cases and identify ways to intervene and reduce the risk to the individuals involved. These crossagency meetings provide an infrastructure through which a more comprehensive understanding of the case details and the levers available to address victims' needs is possible. 
Because this state does not have a firearm sale database, law enforcement officers do not have a central resource for assessing whether batterers in these cases may be in possession of firearms they legally obtained prior to the DVRO or criminal conviction. Bringing together the professionals who are in contact with the people in the cases reviewed provides more sources of information about whether illegally possessed firearms are contributing to the risk and how to remove them than if these organizations were working independently.

The presence of an existing IPV infrastructure is important to the firearms dispossession processes we heard described. The coalitions in both jurisdictions engage in active, collaborative reviews of individual cases. Partners work with victims who are engaged with the criminal justice and/or social service systems. High risk relationships and periods of high risk for victims served by coalition partners are known and discussed among partners with the goal of identifying options for reducing risk. This active engagement with individuals in particularly dangerous relationships, and the team effort to address those risks is a key feature of the two coalition jurisdictions we report on here. These coalitions are more than a set of agencies and organizations with similar missions; the coalition model partners we observed are highly integrated, and assuring firearms dispossession occurs among those prohibited under DVROs is one tool they use in their response.

\section{Practice and Theory: Implications of the Four Cases}

The four case jurisdictions featured herein address the central aim of this research to document and describe the processes in place for dispossessing newly prohibited IPV offenders. These findings add to the gun violence prevention policy literature, and have implications for how local jurisdictions implement and enforce state laws prohibiting firearm possession by respondents to civil DVROs, criminal restraining orders, those convicted of domestic violence misdemeanors, and possibly other categories of prohibited people. We note that the jurisdictions in the four states examined include one where, in the absence of a state prohibition on firearms purchase and possession by domestic violence offenders, implementers relied on state law that requires compliance with federal law. We also consider these cases in the context of Kingdon's agenda setting theory and assess whether this policy formulation theory can explain the implementation processes documented through this multiple case study.

\section{Considering Kingdon's Agenda Setting Theory: Implications for Implementation}

Kingdon's explanation of policy agenda setting points to the convergence of a problem, a policy solution, and supportive politics that may be shaped by a policy entrepreneur with an interest in affecting a policy outcome. This conceptualization of the policy formulation process resonated with our observation of the implementation processes revealed through the four case studies.

The Role of the Problem Across the four jurisdictions, interviewees described the risks associated with armed batterers in ways that reflected their deep understanding of domestic violence broadly. This understanding solidified the problem among implementers and justified investment of resources to address this problem. With the exception of State 2, the risk of armed batterers was a problem consistent with a local domestic violence initiative underway (States 3 and 4) or complementary to a gun violence prevention focus of the implementing agency's leadership (State 1).

The Role of Policy In this study of policy implementation, the role of policy is perhaps most noteworthy in terms of the myriad ways implementers worked within the bounds of existing state law to develop processes and enforce firearm dispossession by newly prohibited possessors, even in the absence of explicit authority within state law. This suggests implementers have a central role in determining how and whether implementation occurs. Our case jurisdictions are located in states with different laws about firearm possession and domestic violence, including one state where the relevant firearm restriction comes exclusively from federal law (Table 2). Despite these differences, all four jurisdictions had processes underway to facilitate dispossession of firearms by those no longer legally qualified to possess them under state and/or federal law. Our findings do not speak to any differences in the reach of these implementation efforts, their impact on guns illegally possessed, or measures of safety in violent relationships. While differences in state law appear not to determine whether agencies in this purposefully selected sample implement and enforce firearm dispossession once individuals are prohibited from possessing firearms, the presence and nuances of such state laws likely affect the scope and impact of these efforts on outcomes since who is prohibited varies among the states. That said, the particulars of any state's firearm prohibition policy may be less important to understanding the implementation efforts than stakeholders' actions and motivations for assuring these laws are more than words on paper. The extent to which implementers view firearm dispossession as a policy strategy that is responsive to the problem of armed batterers and worth prioritizing appears central to understanding whether and how these laws are implemented.

The Role of Politics The politics of implementation we observed in the four case jurisdictions are defined by intra- and inter-agency relations. Unlike Kingdon's conceptualization of 
the politics stream in the context of agenda setting where public opinion is prominent, the politics of implementation in the four case jurisdictions are more insular, reflecting the voices of agency and organization stakeholders. Within States 1 and 2 jurisdictions, where we identified the independent model of implementation, interviewees described approval and support from their agency leadership and a lack of interest from potential partner agencies as defining both the ability to engage in implementation and the scope of their implementation activities. While intra-agency politics were not unimportant in the coalition model jurisdictions in States 3 and 4, interviewees emphasized relationships among agencies and organizations as central to their implementation efforts. The ability to engage across multiple groups to advance implementation by reviewing IPV cases, sharing information, and agreeing on a strategy to increase victim safety depends on strong partner relations and a shared mission. Although the processes through which the four jurisdictions accomplished implementation varied, the politics as reflected in leadership support and/or highly functional partnerships, were consistent.

The Role of People as Entrepreneurial Implementers In addition to the problem, policy, and politics streams of Kingdon's framework, the prominent role of people who serve as policy entrepreneurs and bring these streams together is particularly important to understanding implementation in the four case jurisdictions. Common across the four jurisdictions were people who were knowledgeable about the problem of IPV and the risks associated with firearms in violent partner relationships. Interviewees conveyed a nuanced understanding of the complexities of IPV, spoke with empathy about the victims in these relationships, and described firearms as a risk that should be removed in accordance with the law. In most cases this expertise originated from years of experience working on the issue; in one jurisdiction the expertise originated in gun violence prevention and evolved to incorporate IPV. In describing their implementation activities, interviewees relayed the extra efforts they undertook initially to establish the implementation and enforcement efforts that are the focus of this study. From advocating to an agency head to invest in the infrastructure needed to do the work (State 1), to identifying new ways to interpret and apply broader statute to incorporate gun dispossession into routine practice (State 2), to responding to changes in state law that facilitate gun dispossession by establishing processes and protocols that make those laws actionable (State 3), to advocating for greater attention to guns and gun dispossession within domestic violence response teams (State 4), individuals in each of the jurisdictions championed the implementation and enforcement efforts reported herein.

Interviewees attributed leaders' support from within their organizations as one factor that makes these dispossession efforts possible. Leadership support translated into tangible benefits including resources to develop a dispossession tracking system, time in the schedule to organize and manage dispossession processes, as well as less tangible supports such as encouragement and prioritizing this work.

\section{Criminal Restraining Orders and DVROs: Implications for Policy and Practice}

Across the four jurisdictions we examined, the differences among them were stark. State laws on domestic violence and guns spanned from State 2 with no state law to State 1 with a comprehensive set of laws. The four states exist in different regions of the country, and the jurisdictions we included reflect both large metropolitan centers with Democratic leadership and voters as well as smaller cities with consistently Republican leadership and a conservative voter base. However, in each jurisdiction we documented efforts to dispossess newly prohibited domestic violence offenders of their guns, consistent with federal and/or state law regarding criminal restraining orders and/or domestic violence misdemeanors. For the two jurisdictions in States 3 and 4 those efforts also included civil DVROs. Despite these differences, the recognition by key stakeholders of the heightened risk associated with armed individuals who the court determined to be violent against their partners and the presence of law (at either the federal and/or the state level) led to a deliberate set of decisions in each locality to assure firearm possession prohibitions were implemented and enforced.

The four jurisdictions provide evidence of the varied political and policy contexts in which implementation of DVRO and criminal restraining order firearm prohibitions are occurring. Across the jurisdictions, several lessons for practice are evident and can inform the practice of implementation and enforcement of firearm prohibitions for these orders. Here we discuss seven lessons.

Implementation requires deliberate action. Laws that prohibit firearm possession by respondents to DVROs, criminal restraining orders, or those convicted of domestic violence are not self-executing. Stakeholders from agencies and organizations can advocate for implementation and enforcement of existing firearm prohibition policies. Leveraging opportunities and other similar collaborative problem-solving infrastructures to highlight the value and feasibility of implementing and enforcing firearm prohibitions can bring a focus to this strategy, as demonstrated in State 4. Similarly, advocacy for implementing these laws from within an agency can also be effective, as the findings from the State 1 jurisdiction demonstrate. Concerted implementation and enforcement of these provisions is needed in order to realize the potential benefits of these laws.

Implementation happens in diverse contexts. We identified implementation and enforcement processes in jurisdictions 
with a range of domestic violence laws prohibiting firearm possession by offenders. In each case, local implementation and enforcement processes were in place, suggesting that such practices can be developed to be responsive to the policy context in which they exist. For example, in State 2 where no state prohibitory laws exist, a mechanism to hold probationers and parolees accountable to federal law prohibitions is being used to dispossess those convicted of domestic violence crimes.

Implementation strategies include several sources for identifying whether newly prohibited people possess guns. Stakeholders in all four of the case jurisdictions described processes for assessing whether and how many guns newly prohibited people own. While only one jurisdiction had access to a state record of sale database, law enforcement in all jurisdictions described their strategies for collecting information about gun access by prohibited individuals. Criminal justice records, recorded jail conversations, information from victims, and social media were all sources that law enforcement used to investigate firearm possession by newly prohibited people. The absence of a record of sale database is not a barrier to implementation and enforcement in the three jurisdictions we examined that do not have such a resource.

Implementation leadership was common among the four jurisdictions. Leaders who prioritize firearm dispossession for those prohibited due to domestic violence violations are needed. Advocacy for stronger laws complemented local domestic violence prevention efforts underway in State 3 and supported incorporating firearm dispossession in their domestic violence services and response. Within agencies and organizations, leaders who build the procedural pathway for the local context to implement firearm prohibitions are another type of leadership observed in the case jurisdictions. As demonstrated in State 2 with the prosecutor/parole and probation partnership, these policy entrepreneurs identified the problem of gun access in violent, intimate relationships and developed a policy implementation solution consistent with state law. Demonstrations of leadership were present in all four jurisdictions and offer examples for future efforts to realize implementation of these laws.

Implementers have deep expertise in and commitment to domestic violence. Within all four jurisdictions, those responsible for implementation and enforcement were knowledgeable about IPV, well versed in gun laws, connected with the various stakeholders involved, and committed to improving victim services and supports. This expertise is likely one explanation for how the focus on implementation within these jurisdictions evolved. Implementers in the four cases applied their knowledge of existing policy and how policy can be used to address the problem associated with the risk of armed abusers through implementation. Investing in people to develop an understanding of the trajectories of violent relationships, known risk factors, and evidence-informed policies and programs to effectively intervene to reduce the risk and interrupt these trajectories will be valuable to future implementation efforts that aim to realize firearm dispossession among those newly prohibited because of domestic violence.

Implementation processes are tailored to the local context. Two models of implementation and enforcement were evident in the four jurisdictions. Within each of those models, the stakeholders involved had different processes for accomplishing implementation and enforcement. For example, while the jurisdictions in States 1 and 2 shared similar approaches with their independent models, the policies they implemented (state criminal restraining order laws in State 1; state law requiring people on parole and probation to comply with federal laws in State 2), the populations they targeted, and how they assessed firearm ownership by prohibited people (the state record of sale database in State 1; a combination of administrative criminal justice records and public information in State 2) were some of the ways in which implementation processes reflected the context in which they work. While the independent and coalition models described here provide general approaches to implementing laws that prohibit batterers from possessing firearms, attention to the context when developing specific processes is needed.

Kingdon's agenda setting framework is informative for understanding implementation. Variations of each of the three streams are present in the four cases and provide a model for explaining the implementation activities underway. In all four cases the convergence of the three streams can be understood as the product of one or more implementation entrepreneurs. These individuals are the instigators that viewed the problem of domestic violence and guns as one that could be addressed through the policy solution of firearm dispossession, and managed the local politics to realize implementation in their jurisdictions.

\section{Limitations}

The case descriptions here and the theoretical and practice implications proposed offer new insight into the implementation processes involved with dispossessing newly prohibited IPV offenders from their firearms. These findings should be considered within the context of the limitations of the approach we used to address our study aims. First, this study was not designed to be generalizable and the findings should not be interpreted as such. With the selected states our sample includes regional diversity, and the within state jurisdictions reflect different gun cultures. We employed this sampling 
strategy to explore implementation processes in a range of contexts where firearm dispossession of newly prohibited IPV offenders is occurring. Importantly, by selecting only jurisdictions where implementation is occurring, our sample does not reflect the many jurisdictions where no implementation of firearm dispossession for newly prohibited domestic violence offenders is happening. The barriers to implementation in nonimplementing jurisdictions are important to understand, and should be a topic of future research.

Given that this research was a qualitative endeavor focused on development and mechanics of firearm dispossession processes, we did not collect data on fidelity to the process or numbers of newly prohibited individuals dispossessed of firearms. We therefore cannot make any claims as to how effectively these processes are being implemented. We also do not know the breadth of the population to which these efforts may apply (for example, the number of individuals in State 1, or the nation, who are prohibited from possessing guns because of a domestic violence order or offense).

\section{Strengths}

Despite the limitations noted, this research has merit. The presence of firearms in a violent intimate relationship increases the risk that the violence will become fatal. The available evidence suggests that removing firearms from intimate partners who are violent and subject to a civil DVRO is associated with reductions in intimate partner homicide (Zeoli et al. 2018), and that implementation does not always happen - resulting in missed opportunities for effective intervention (Frattaroli and Teret 2006; Webster et al. 2010). Understanding how implementation of these laws and other laws that prohibit IPV offenders from possessing firearms, and identifying a theoretical explanation for their uptake can provide concrete guidance to law enforcement and other stakeholders about how to address the gap that exists in many jurisdictions between policy and practice.

The strength of these contributions is particularly noteworthy given the scant attention to implementation of laws that prohibit firearm possession by certain groups generally, and the absence of attention to criminal restraining orders and those prohibited because of criminal intimate partner crimes in particular. Assuring that these laws are implemented is a common-sense strategy for reducing the risk that IPV will become lethal.

As evidenced by the experiences documented about the four jurisdictions, there are many ways to accomplish implementation and enforcement of civil DVRO and criminal restraining order laws that prohibit firearm possession. Importantly, implementation and enforcement are occurring in jurisdictions with diverse policy responses in place to address the risks associated with batterers who have ready access to firearms, and where the politics are different shades of red and blue.

Open Access This article is licensed under a Creative Commons Attribution 4.0 International License, which permits use, sharing, adaptation, distribution and reproduction in any medium or format, as long as you give appropriate credit to the original author(s) and the source, provide a link to the Creative Commons licence, and indicate if changes were made. The images or other third party material in this article are included in the article's Creative Commons licence, unless indicated otherwise in a credit line to the material. If material is not included in the article's Creative Commons licence and your intended use is not permitted by statutory regulation or exceeds the permitted use, you will need to obtain permission directly from the copyright holder. To view a copy of this licence, visit http://creativecommons.org/licenses/by/4.0/.

\section{References}

Campbell, J. C., Webster, D., Koziol-McLain, J., Block, C., Campbell, D., Curry, M. A., Gary, F., Glass, N., McFarlane, J., Sachs, C., Sharps, P., Ulrich, Y., Wilt, S. A., Manganello, J., Xu, X., Schollenberger, J., Frye, V., \& Laughon, K. (2003). Risk factors for femicide in abusive relationships: Results from a multisite case control study. American Journal of Public Health, 93(7), 10691097. https://doi.org/10.2105/ajph.93.7.1089.

Castillo-Carniglia, A., Kagawa, R. M. C., Webster, D. W., Vernick, J. S., Cerda, M., \& Wintemute, G. J. (2018). Comprehensive background check policy and firearm background checks in three US states. Injury Prevention, 24(6), 431-436. https://doi.org/10.1136/ injuryprev-2017-042475.

Castillo-Carniglia, A., Webster, D. W., \& Wintemute, G. J. (2019). Effect on background checks of newly-enacted comprehensive background check policies in Oregon and Washington: A synthetic control approach. Injury Epidemiology, 6(45), 1-6. https://doi.org/10. 1186/s40621-019-0225-8.

Creswell, J. W. (2007). Qualitative inquiry and research design: Choosing among five approaches (2nd ed.). Sage Publications, Inc.

Diez, C., Kurland, R. P., Rothman, E. F., Bair-Merritt, M., Fleegler, E., Xuan, Z., et al. (2017). State intimate partner violence-related firearm laws and intimate partner homicide rates in the United States, 1991 to 2015. Annals of Internal Medicine, 167(8), 536-543. https:// doi.org/10.7326/M16-2849.

Diviney, C. L., Parekh, A., \& Olson, L. M. (2009). Outcomes of civil protective orders: results from one state. J Interpers Violence., 24(7), 1209-1221. https://doi.org/10.1177/0886260508322185.

Folkes, S. E. F., Hilton, N. Z., \& Harris, G. T. (2013). Weapon use increases the severity of domestic violence but neither weapon use nor firearm access increases the risk or severity of recidivism. Journal of Interpersonal Violence, 28(6), 1143-1156. https://doi. org/10.1177/0886260512468232.

Fox, J. A., \& Fridel, E. E. (2017). Gender differences in patterns and trends in U.S. homicide, 1976-2015. Violence and Gender, 4(2), $37-43$.

Frattaroli, S., \& Teret, S. P. (2006). Understanding and informing policy implementation: A case study of the domestic violence provisions of the Maryland gun violence act. Evaluation Review, 30(3), 347-360. https://doi.org/10.1177/0193841X06287684.

Gun Control Act of 1968, 18 U.S.C. §922(g)(8) (1994).

Gun Control Act of 1968, 18 U.S.C. §922(g)(9) (1996).

Hahn, A. (2018). Toward a uniform domestic violence civil protection order law. Seton Hall Law Review, 48(3), 897-929. 
Keilitz, S. L., Hannaford, P. L., Efkeman, H. S. (1997). Civil protection orders: The benefits and limitations for victims of domestic violence. National Center for State Courts. http://www.ncjrs.gov/App/ publications/abstract.aspx?ID=172223

Kingdon, J. W. (2011). Agendas, alternative, and public policies, (2nd ed.). Glenview: Pearson.

Lynch, K. R., \& Logan, T. K. (2015). "You better say your prayers and get ready": Guns within the context of partner abuse. Journal of Interpersonal Violence, 33(4), 686-711. https://doi.org/10.1177/ 0886260515613344.

Marshall, M. N. (1996). The key informant technique. Family Practice, $13,92-97$.

Miles, M. B., \& Hubermna, M. A. (1994). Qualitative data analysis: An expanded sourcebook. Thousand Oaks: Sage Publications, Ltd..

Miller, M., Hepburn, L., \& Azrael, D. (2017). Firearm acquisition without background checks: Results of a national survey. Annals of Internal Medicine, 166(4), 233-239. https://doi.org/10.7326/M16-1590.

Moracco, K. E., Clark, K. A., Espersen, C., \& Bowling, J. M. (2006). Preventing firearms violence among victims of intimate partner violence: An evaluation of a new North Carolina law. Washington, DC: U.S. Department of Justice.

Patton, M. Q. (2002). Qualitative research and evaluation methods (3rd ed.). Thousand Oaks, CA: Sage Publications Inc.

Prosecutors Against Gun Violence \& The Consortium for Risk-Based Firearm Policy. (2016). Firearm removal/retrieval in cases of domestic violence. Washington, DC: Educational Fund to Stop Gun Violence.

Richards, T. N., Jennings, W. G., Tomsich, E. A., \& Gover, A. R. (2013). A longitutidinal examination of offending and specialization among a sample of Massachusetts domestic violence offenders. Journal of Interpersonal Violence, 28(3), 643-663. https://doi.org/10.1177/ 0886260512455519.

Saltzman, L. E., Mercy, J. A., O'Carroll, P. W., Rosenberg, M. L., \& Rhodes, P. H. (1992). Weapon involvement and injury outcomes in family and intimate assaults. JAMA, 267(22), 3043-3047.

Smith, S. G., Fowler, K. A., \& Niolon, P. H. (2014). Intimate partner homiicde and corollary victims in 16 states: National Violent Death Reporting System, 2003-2009. American Journal of Public Health, 104(3), 461-466. https://doi.org/10.2105/AJPH.2013.301582.

Smucker, S., Kerber, R. E., \& Cook, P. J. (2018). Suicide and additional homicides associated with intimate partner homicide: North Carolina 2004-2013. Journal of Urban Health, 95, 337-343. https://doi.org/10.1007/s11524-018-0252-8.

Sorenson, S. B. (2017). Guns in intimate partner violence: Comparing incidents by type of weapon. Journal of Women's Health, 26(3), 249-258. https://doi.org/10.1089/jwh.2016.5832.

Sorenson, S. B., \& Schut, R. A. (2018). Nonfatal gun use in intimate partner violence: A systematic review of the literature. Trauma, Violence, \& Abuse, 19(4), 431-442. https://doi.org/10.1177/ 1524838016668589 .

Sorenson, S. B., \& Wiebe, D. J. (2004). Weapons in the lives of battered women. American Journal of Public Health, 94(8), 1412-1417. https://doi.org/10.2105/ajph.94.8.1412.
Sullivan, T. P., \& Weiss, N. H. (2017). Is firearm threat in intimate relationships associated with posttraumatic stress disorder symptoms among women? Violence and Gender, 4, 31-36. https://doi. org $/ 10.1177 / 0886260517736274$.

Sullivan, T. P., Price, C. E., Weiss, N. H., \& Pugh, N. E. (2017). Criminal protective orders as a critical strategy to reduce domestic violence. Washington, DC: Office of Justice Programs' National Criminal Justice Reference Service.

Tjaden, P., \& Thoennes, N. (2000). Full report on the prevalence, incidence, and consequences of violence against women: Findings from the National Violence against Women Survey. Washington, D.C.: National Institutes of Justice and Centers for Disease Control and Prevention.

Truman, J. L., \& Morgan, R. (2014). Nonfatal domestic violence, 2003 2012. Washington, D.C.: Department of Justice.

Vigdor, E. R., \& Mercy, J. A. (2006). Do laws restricting access to firearms by domestic violence offenders prevent intimate partner homicide? Evaluation Review, 30(3), 313-346. https://doi.org/10. 1177/0193841X06287307.

Webster, D. W., Frattaroli, S., Vernick, J. S., O'Sullivan, C., Roehl, J., \& Campbell, J. C. (2010). Women with protective orders report failure to remove firearms from their abusive partners: Results from an exploratory study. Journal of Women's Health, 19(1), 93-98. https://doi.org/10.1089/jwh.2007.0530.

Wintemute, G. J., Frattaroli, S., Claire, B. E., Vittes, K. A., \& Webster, D. W. (2014). Identifying armed respondents to domestic violence restraining orders and recovering their firearms: Process evaluation of an initiative in California. American Journal of Public Health, 104(2), E113-E118. https://doi.org/10.2105/AJPH.2013.301484.

Yin, R. K. (2014). Case study research design and methods, (5th Ed.). Thousand Oaks: Sage Publications, Ltd..

Zeoli, A. M., \& Paruk, J. K. (2019). Potential to prevent mass shootings through domestic violence firearm restrictions. Criminology \& Public Policy, 19(1), 129-145.

Zeoli, A. M., \& Webster, D. W. (2010). Effects of domestic violence policies, alcohol taxes and police staffing levels on intimate partner homicide in large US cities. Injury Prevention, 16(2), 90-95. https:// doi.org/10.1136/ip.2009.024620.

Zeoli, A. M., McCourt, A., Buggs, S., Frattaroli, S., Lilley, D., \& Webster, D. W. (2018). Analysis of the strength of legal firearms restrictions for perpetrators of domestic violence and their associations with intimate partner homicide. American Journal of Epidemiology, 187(11), 2365-2371. https://doi.org/10.1093/aje/ kwy174.

Zeoli, A. M., Frattaroli, S., Roskam, K., \& Herrera, A. K. (2019). Removing firearms from those prohibited from possession by domestic violence restraining orders: A survey and analysis of state laws. Trauma, Violence, \& Abuse, 20(1), 114-125. https://doi.org/ $10.1177 / 1524838017692384$.

Publisher's Note Springer Nature remains neutral with regard to jurisdictional claims in published maps and institutional affiliations. 